\title{
PASSIVE BARRIERS TO INADVERTENT HUMAN INTRUSION FOR USE AT THE NEVADA TEST SITE
}

\author{
June 2007
}

Prepared for:

The United States Department of Energy National Nuclear Security Administration Nevada Site Office

Work Performed Under Contract No. DE-AC52-06NV25946

Prepared by:

National Security Technologies LLC

P. O. Box 98521

Las Vegas, Nevada 89193-8521 


\section{Disclaimer}

Reference herein to any specific commercial product, process, or service by trade name, trademark, manufacturer, or otherwise, does not necessarily constitute or imply its

endorsement, recommendation, or favoring by the United States Government or any agency thereof or its contractors or subcontractors.

\section{Availability Statement}

Available for sale to the public from:

U.S. Department of Commerce

National Technical Information Service

5285 Port Royal Road

Springfield, VA 22161-0002

Telephone: (800) 553-6847

Fax: (703) 605-6900

E-mail: orders@ntis.gov

Online ordering: http://www.ntis.gov/ordering.htm

Available electronically at http://www.osti.gov/bridge

Available for a processing fee to the U.S. Department of Energy and its contractors, in paper, from:

U.S. Department of Energy

Office of Scientific and Technical Information

P.O. Box 62

Oak Ridge, TN 37831-0062

Telephone: (865) 576-8401

Fax: (865) 576-5728

E-mail: reports@adonis.osti.gov 


\section{Contents}

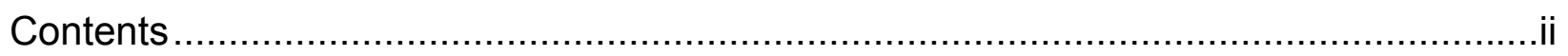

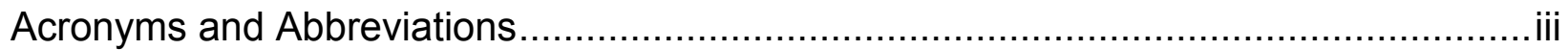

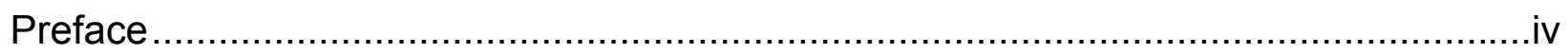

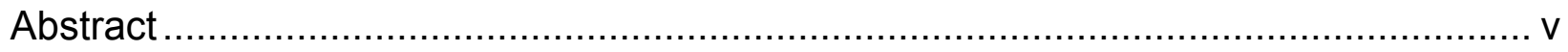

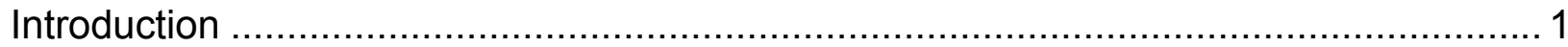

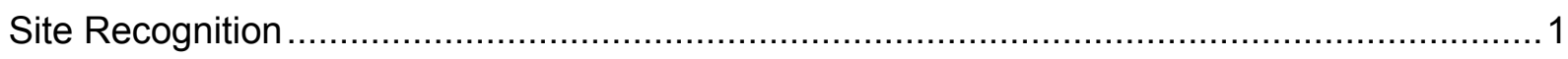

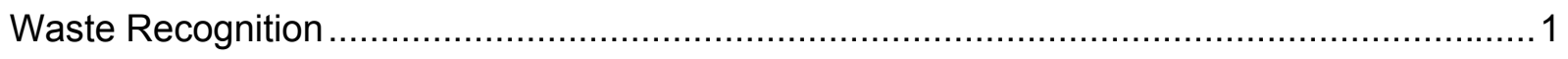

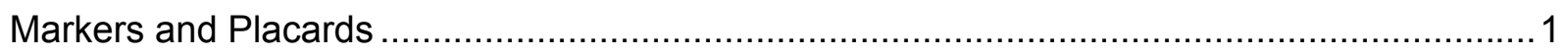

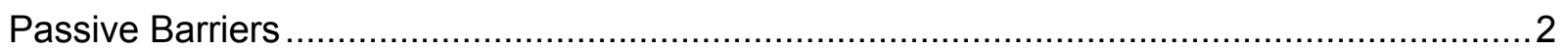

Barriers Thought Most Appropriate for Use at NTS ............................................. 2

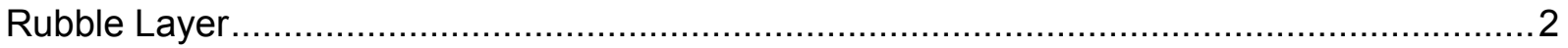

Tire Layer

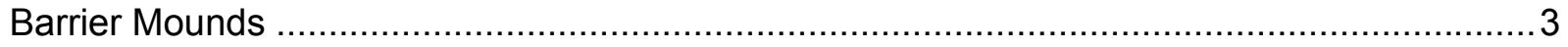

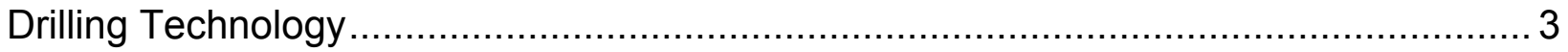

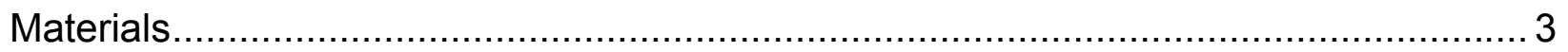

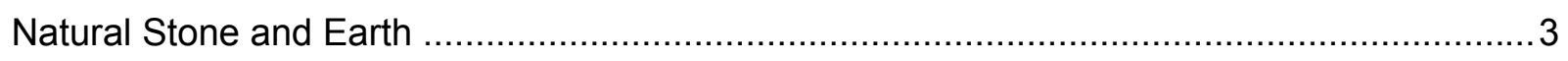

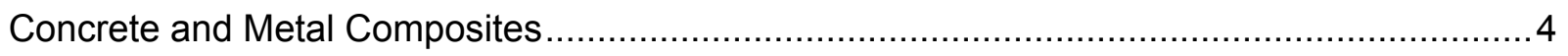

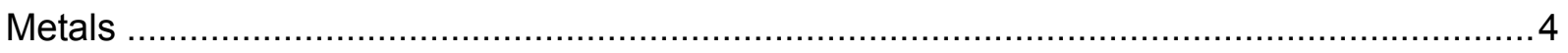

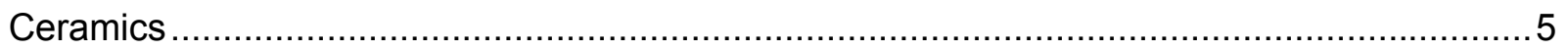

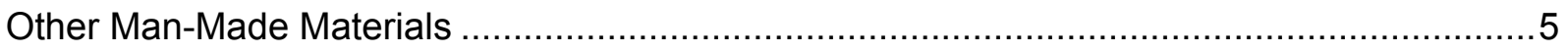

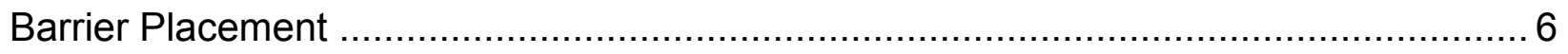

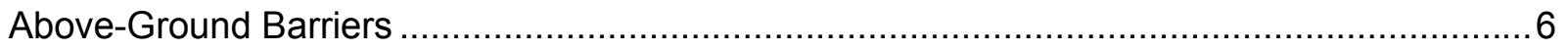

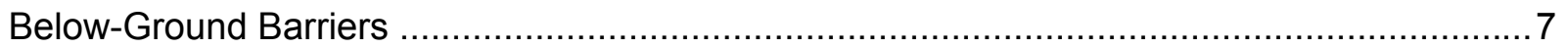

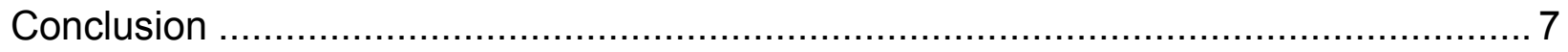

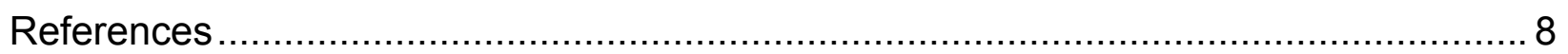




\section{Acronyms and Abbreviations}

$\begin{array}{ll}\text { BN } & \text { Bechtel Nevada } \\ \mathrm{cm} & \text { centimeter } \\ \text { DOE } & \text { U.S. Department of Energy } \\ \text { IHI } & \text { inadvertent human intruder } \\ \text { m } & \text { meter } \\ \text { NSTec } & \text { National Security Technologies, }{ }^{\text {LLC }} \\ \text { NTS } & \text { Nevada Test Site } \\ \text { PA(s) } & \text { performance assessment(s) } \\ \text { RWMS } & \text { Radioactive Waste Management Site }\end{array}$




\section{Preface}

National Security Technologies, LLC (NSTec), under contract to the U. S. Department of Energy (DOE) National Nuclear Security Administration Nevada Site Office (NNSA/NSO), is conducting closure planning activities for the Area 3 and Area 5 Radioactive Waste Management Sites (RWMS) at the Nevada Test Site (NTS). These facilities have been extensively studied and characterized over the past two decades. A great deal of characterization and performance assessment work was completed by previous contractors and documented in reports with very limited distribution. To support closure planning, NSTec is preparing several of these limiteddistribution reports for public release so that the reports will be more broadly accessible.

In July1996, Bechtel Nevada (BN) transmitted Passive Barriers to Inadvertent Human Intrusion for Use at the Nevada Test Site to the United States Department of Energy, under Contract DE-AC08-91NV10833. The paper identifies types of passive barriers that could be used to deter future water well drilling into buried low level waste. The paper was developed in support of performance assessments prepared to meet the requirements of DOE Order 5820.2A, and later, by DOE Order 435.1, Radioactive Waste Management. Since the development of this paper in 1996, factors affecting inadvertent human intrusion have been examined further. The likelihood of future well development, within the RWMSs, during the compliance period, is considered low. The site conditions are not well-suited to grazing, raising agricultural crops, or water resource development. Existing institutional controls, including use restrictions and access controls, upgradient groundwater quality issues from past land uses, the availability of more accessible spring and groundwater within the region, and other factors, significantly reduce the risk of future drilling in the RWMSs. Although well drilling is now considered an unlikely action to disturb the buried waste, passive barrier features continue to be evaluated as part of the performance assessment work for transuranic (TRU) waste units at the Area 5 RWMS, which must meet the assurance requirements of Title 40 CFR 191.14

NSTec made minor revisions to the $1996 \mathrm{BN}$ edition to conform to current editorial standards of the NNSA/NSO and to meet current security requirements for public release. The abstract was added to meet current requirements for electronic distribution on the DOE Office of Scientific and Technical Information (OSTI) Information Bridge public website. The report has not otherwise been updated. This 2007 NSTec edition has been reviewed and approved by one of the principal authors of the original 1996 report.

Further information is available through the DOE OSTI (http://www.osti.gov/bridge/index.jsp). 


\section{Abstract}

In July1996, BN transmitted Passive Barriers to Inadvertent Human Intrusion for Use at the Nevada Test Site to the United States Department of Energy, under Contract

DE-AC08-91NV10833. The 1996 paper had a limited distribution and was not reviewed for public release. In 2007, National Security Technologies LLC (NSTec) made minor revisions to conform to current editorial standards of the NNSA/NSO and to meet current security requirements for public release.

The primary purpose of this study was to identify types of engineered passive barriers that could deter future intrusion into buried low-level radioactive waste, particularly intrusion by drilling water wells.

The study considered drilling technology, many natural and man-made materials, and both underground and above-ground barriers. Based on cost and effectiveness, the report recommended underground barriers consisting of a layer of rubble or tires. An aboveground barrier mound might also prove effective, but would cost more, and may become an attractive nuisance (e.g., might, after their purpose has been forgotten, encourage exploration for the sake of satisfying curiosity). Advances in drilling technology could render any engineered barriers ineffective if there is motivation to penetrate the barriers. 


\section{Introduction}

The purpose of this study is to consider materials, locations, and types of engineered passive barriers that could deter intrusion into buried low-level radioactive waste in the form of drilling water wells.

Inadvertent human intrusion occurs if a person who is unaware that waste is buried at a given location, (such as the Area 3 or Area 5 Radioactive Waste Management Sites (RWMSs) at the Nevada Test Site [NTS]), and comes into contact with that waste. Although contact could occur through many mechanisms, such as mining, nonnuclear waste disposal, sabotage, and war (Tolan, 1993), the scenario judged most likely, and the standard scenario used in performance assessments (PAs), is the drilling of water wells.

Active institutional control of a waste disposal site is generally assumed to cover the first 100 years after site closure. Unless institutional control is lost due to social or political upheaval, a possibility not considered here, inadvertent human intrusion is impossible during this period. For the remaining 9,900 years of the 10,000 years of the PA time frame, other measures are used to decrease the chance that the inadvertent human intruder (IHI) will drill a water well into the waste. These measures include:

- Site Recognition

- Waste Recognition

- Markers and Placards

- Passive Barriers

\section{Site Recognition}

Knowledge of the NTS could endure for thousands of years, perhaps for the entire 10,000-year compliance period. Unusual surface features, such as subsidence craters, could endure for thousands of years, perhaps for the entire 10,000-year compliance period. Such knowledge, along with the distinctive surface features, might serve to warn away potential intruders.

\section{Waste Recognition}

A potential IHI might, on drilling into waste, recognize the waste as dangerous and immediately abandon the site. This would prevent the intruder from receiving a chronic dose, such as would arise from living atop soil contaminated by drill cuttings. However, it would not eliminate the acute dose received from exposure to the drill cuttings as they are brought to the surface.

\section{Markers and Placards}

Markers (a small number of large monoliths, many small markers, chemical markers, or layers of unusual soil or rock) could serve to warn the potential IHI of the danger. Colored dyes, which color the recirculating drill fluid and call attention to the drillings having encountered unusual conditions, are discussed in Tolan (1993) and should be considered as a kind of marker. 


\section{Passive Barriers}

The potential for engineered passive barriers to deter the drilling of a water well that inadvertently passes through the waste is the focus of this paper. Engineered barriers, which make drilling a water well more difficult, might prevent the potential IHI from drilling into the waste. However, it must be noted that a sufficiently determined driller, with access to advanced drilling technology, will be able to penetrate any practical barrier.

This report describes the types of engineered barriers thought most appropriate for use at the NTS. In support of these conclusions, assumptions about drilling technologies are stated. Materials considered in the literature for engineered barriers, whether or not these materials are considered appropriate for use at the NTS, and the location of barriers, are discussed. Finally, conclusions are stated.

\section{Barriers Thought Most Appropriate for Use at NTS}

Two forms of underground engineered barriers are recommended for use at the NTS. These decisions are made on the basis of relatively low cost and judged effectiveness. The recommended barriers are as follows:

- Rubble Layer

- Tire Layer

- Barrier Mounds

\section{Rubble Layer}

A layer of loose rubble (or loosely packed, approximately spherical rocks) would prove an impediment to many types of drilling and would be a serious impediment to rotary-wash drilling. However, such a layer would be a minimal barrier against coring equipment. The cost of emplacing a layer is relatively low. Since the layer would be constructed of geologic materials, it should remain in place most, if not all, of the 10,000-year compliance period. In view of cost, effectiveness, and longevity, this barrier is the one most likely to be implemented at NTS.

To reduce chemical and physical weathering effects to the rubble layer, rock types composed of silica-rich minerals, which are stable at the surface of the earth, should be used. Silica-rich rocks include quartzites and granites and are readily available on the NTS. Outcrops of Eureka Quartzite, a thick-bedded vitreous orthoquartzite, are found along the eastern edge of Yucca Flat and in the southern part of Frenchman Flat. The Gold Meadows and Climax Stocks, generally considered medium- to coarse-grained porphyritic granodiorites, are found northwest and north of Yucca Flat, respectively. Rock quarrying would be necessary for all but Climax Stock. Excavated rock from the Climax Mine might be the most viable source for rubble layer material.

\section{Tire Layer}

A layer of tires would be an impediment to many types of drilling, possibly even causing equipment damage. The longevity of such a layer is difficult to assess; no studies of the rate of degradation of rubber in arid environments have been found. However, the cost of placing such a layer would be minimal. The likelihood of installing such a barrier at NTS is reasonably high, but is lower than that of the rubble layer. 


\section{Barrier Mounds}

This above-ground barrier might also prove effective. Barrier mounds are above-ground mounds situated directly above the waste to induce the driller to move to either side of the mound to avoid drilling through the additional thickness. Barrier mounds considered for use at the U.S. Department of Energy (DOE) Hanford Reservation are 5.4 meters (m) thick (U.S. DOE, 1987). Snyder et al. (1995) found evidence that the location of the Area 5 RWMS has been aggrading since the middle Quaternary, and the maximum depth of local channel erosion is less than $1.5 \mathrm{~m}$. While this might or might not hold for the Area 3 RWMS, it shows that, at least, a mound at the Area 5 RWMS would be unlikely to erode away. Barrier mounds have the advantage that warning markers could be buried within them, which would provide a deterrent to excavation, if not to drilling. However, the cost of constructing structures as massive as the barrier mounds considered for use at the Hanford Reservation might be great, and its impact on the planned closure of the RWMSs is unknown. Hence, such barriers are only moderately likely to be installed at NTS.

Support for the choices of these barriers follows, regarding materials and locations of barriers that have been considered.

\section{Drilling Technology}

Drilling technology will most likely continue to change, as it has in the past. However, the nature of these changes cannot be predicted for any but the shortest intervals of time. Attempts to predict how drilling technology will develop over the next 10,000 years (Hora et al., 1991), in the context of waste disposal, have resulted in consideration of such futuristic technologies as semiautonomous mining machines, completely autonomous "mole miners," and nanotechnology. Such technologies might or might not ever be developed. Hence, while acknowledging that technological advances are inevitable, discussion here will focus on current drilling technology.

\section{Materials}

The effectiveness of any passive barrier depends crucially on the construction materials. Materials could be considered unacceptable for constructing barriers either because they are ineffective (i.e., do not significantly slow the drill bit) or have insufficient longevity (i.e., do not last for an appreciable portion of the 10,000-year PA time frame in the NTS environment.) Materials considered for use in passive-engineered barriers include the following:

- Natural stone and earth

- Concrete and metal composites

- Metals, including metal and polymer composites

- Ceramics

- Other man-made materials

\section{Natural Stone and Earth}

There are two types of natural stone barriers: solid barriers and layers of loose stone. Since drillers expect to encounter and penetrate solid stone barriers, the effectiveness of such barriers is relatively low. Loose stone barriers can, depending on the type of drilling being employed, prove highly effective. Drilling through a layer of loose rubble or similar loosely packed stones 
with a rotary wash drilling system is difficult. Therefore, a layer of loose natural stone might be beneficial if a rotary wash drilling system is used.

Natural stone barriers have the advantage of almost indefinite longevity. Additionally, a layer of nonnative stone might have the advantage of serving as a warning, although questions have been raised about recognizing nonnative stone in the absence of knowing the potential for waste.

While earth is not a direct barrier to drilling, barrier mounds have been considered. Barrier mounds are discussed at length in Adams et al. (1981), Fayer et al. (1985), and Phillips and Hartles (1986).

Earth and stone barriers are seriously considered for use at NTS. Materials are readily available and emplacement would not prove difficult. Preliminary cost estimates have indicated that emplacing a layer of approximately $900 \mathrm{~m}^{3}$ (30 m X $\left.30 \mathrm{~m} \mathrm{X} 1 \mathrm{~m}\right)$ of quartzitic sandstone, each stone having a diameter of between 10 and 20 centimeters $(\mathrm{cm})$, would cost approximately $\$ 73,000$ (1996 dollars) if tumbled stone were used and approximately $\$ 40,000$ (1996) if untumbled stone were used.

\section{Concrete and Metal Composites}

Concrete longevity depends on the quality of cement, the aggregate used, the water-to-cement ratio, and the quality of workmanship (Walton et al., 1990). In addition the relatively short history of the modern use of concrete ( $\sim 100$ years) further complicates predicting longevity. Given the highly alkaline chemistry of the soil of NTS and the high-sulfate content of the ground water, it is thought unlikely that concrete structures would survive long.

Pitcher Drilling (Personal Communication, 1996) indicated that steel-reinforced concrete would provide an effective barrier to rotary-wash drilling. Hence, concrete and metal composites might, for as long as they survive, provide effective barriers to at least some forms of drilling. Additionally, coloring the concrete might help provide a warning of previous activity. Therefore, the cost of emplacement is relatively high, the effectiveness is questionable, and the longevity is difficult to assess, making concrete barriers poor choices at the NTS.

\section{Metals}

Metal barriers have the advantage of high-tensile strength and fracture toughness. However, as observed by B. Griggs in Westerman (1980), "The accurate prediction of corrosion behavior of metallic materials for time periods of up to 1,000 years challenges the ability of corrosion science." Extending this prediction by an order of magnitude, to the PA's 10,000-year framework, verges on the impossible.

Many environmental factors, such as $\mathrm{pH}$ of soil and soil water, and dissolved oxygen in soil water, influence corrosion. Other, less obvious factors, further complicate the estimation of longevity of metal barriers. These include:

- Microbiologically influenced corrosion can have a major impact on localized corrosion from the alteration of environmental chemical properties (McCright, 1995). Prediction of microbiologically influenced corrosion is almost impossible, as it depends on which 
microorganisms are inadvertently introduced during construction and what microenvironments they encounter.

- Corrosion potential exists under dry-oxidation conditions (Halsley and McCright, 1987).

The expected magnitude of this corrosion over long periods of time is difficult to estimate.

The effectiveness of metal barriers depends on what metal is selected. Cast iron, for example, would be a poor choice because of its relative softness and high reactivity. Steel would be a more effective barrier, but is probably not the ideal metal to use in engineered barriers. The metals most likely used in metal barriers (Westerman, 1980) are Grade 2 titanium (commercial purity) and Grade 12 titanium ( 0.8 weight percent nickel and 0.3 weight percent molybdenum). Titanium has the advantages of having a high corrosion resistance and a tendency to oxidize into titanium oxide, thereby providing the material with a natural self-healing ceramic coating (Trauth et al., 1993).

The effectiveness of metal barriers depends on the thickness of the barrier. A thin layer of metal, such as the metal wire recommended in Tolan (1993), might temporarily impede a rotary drill, but would prove to be only a minor impediment to more sophisticated drilling technologies. Similarly, thin layers of metal are likely to corrode more rapidly than thick layers. However, economic considerations limit the thickness of metal barriers. A barrier that is judged too expensive to build is of little use.

W. E. Skiens, in Westerman (1980), considers the possibility of combining metals with polymers. Many polymers are resistant to environments in which metals would rapidly corrode, while showing indications of great longevity. While this method is promising, its long-term suitability is currently unknown.

Metal barriers are unlikely to be installed at the NTS. While such barriers could prove effective, given sufficient thickness, cost is likely prohibitive.

\section{Ceramics}

As observed by H. T. Fullam, in Westerman (1980), "It is impossible to estimate, with any degree of reliability, the long-term leach resistance of the materials tested. Extrapolation of the measured leach rates to very long exposure times is difficult, because, in almost all of the tests, the leach rates varied with time." For this reason, assessing the longevity of ceramics is a very difficult task.

Ceramics are generally much less fracture resistant than metals which makes purely ceramic barriers unlikely to be effective. It is possible that a barrier combining metals with ceramics might prove more effective than a barrier consisting solely of either. Ceramic barriers, with or without metal, are not likely to be installed at the NTS. While such barriers could prove effective, given sufficient thickness, cost is likely prohibitive.

\section{Other Man-Made Materials}

Layers of certain other man-made materials could inhibit drilling. For example, Pitcher Drilling (Personal Communication, 1996) indicated that a layer of tires would pose a significant obstacle, 
if certain drilling technologies were used. The longevity of such a layer is difficult to assess. However, the cost of emplacing it may be minimal, especially if the material being placed is of little or no economic value (like old tires). Hence, such layers are to be recommended from a cost/benefit standpoint (very little cost, at least some benefit). Alternately, layers of abrasive materials that might speed up the wearing out of the drill bit might, to some extent, deter intrusion. The effectiveness of such layers depends on the drilling method.

A layer of asphalt would have similar advantages and disadvantages to a layer of concrete. However, if coring equipment is used, asphalt might be more difficult to drill through than concrete, due to asphalt's lower heat dissipation and the binding of asphalt against the outer and inner surfaces of the bit.

Tire barriers are reasonably strong candidates for use at the NTS. While the longevity of the layer is unknown, the cost is minimal, and a tire layer would provide a strong impediment to certain types of drilling.

\section{Barrier Placement}

In general, passive barriers can either be above ground or below ground. Above-ground barriers are subject to weathering and might become "attractive nuisances" (e.g., after their purpose has been forgotten, these barriers might encourage exploration for the sake of satisfying curiosity). Below-ground barriers at the NTS would be subject to corrosion from the extremely alkaline soils and vary in effectiveness with the drilling technology employed. For example, a barrier that blocks rotary-wash drilling might be completely ineffective against other drilling technologies, such as percussive drilling. The effectiveness of any given barrier against future drilling technologies is, by definition, unknown.

\section{Above-Ground Barriers}

The most obvious above-ground barrier is the enduring surface monument or group of monuments. However, such a monument would serve as a warning, rather than an impediment to drilling, and runs the risk of becoming an "attractive nuisance." Above-ground barriers include the following:

- Barrier Mounds. Above-ground mounds situated directly above the waste might induce the driller to move to either side of the mound to avoid having to drill through the additional thickness. Such barrier mounds, $5.4 \mathrm{~m}$ in thickness, are currently under consideration at the DOE Hanford Site (U.S. DOE, 1987). As an additional safeguard against intrusion by excavation, warning markers could be buried within the barrier mound.

- Drill-Rig Emplacement Barriers. Steel poles protruding from the surface, embedded in a layer of below-ground concrete, would render placement of a drill rig difficult as long as the structure stood. Such a structure would be of unknown longevity and might eventually become an "attractive nuisance." A similar concept, the so-called "landscape of thorns," was introduced by M. Brill in Trauth et al., (1993), as a warning rather than a barrier. An additional possibility for a barrier might be concrete triad breakwater pieces, which have four concrete legs arranged along the axes of a tetrahedron. 
Above-ground barriers have the disadvantage that they might be perceived by future generations as a source of raw materials. As an example, the marble slabs that originally covered the exteriors of the pyramids of Egypt were removed for building materials centuries ago.

\section{Below-Ground Barriers}

Below-ground barriers are, among other considerations, limited by life-cycle costs. For example, a 3-m-thick layer of titanium steel atop the waste, coated with polymers to protect it from corrosion, would probably be a highly effective barrier. However, the cost of such a barrier would most likely preclude its use. Below-ground barriers that have been considered include the following:

- Loose rubble, or loosely-packed, approximately spherical rocks

- A layer of reinforced concrete or asphalt, approximately $.5 \mathrm{~m}$ thick

- A layer of plate steel, approximately $2.5 \mathrm{~cm}$ thick

- A layer of tires $1 \mathrm{~m}$ thick

The first two of these would slow, but not stop, drilling. The third could be penetrated by an aggressive driller. The final layer to consider, the tire layer, would temporarily stop drilling, with possible equipment damage; however, penetration is possible.

In general, below-ground barriers are preferred. They do not run the risk of becoming attractive nuisances and are not subject to erosion from wind and weather.

\section{Conclusion}

Three forms of engineered barriers are recommended for possible use at the NTS. Two of these, a rubble layer and a tire layer, are below-ground barriers. The third, a barrier mound, is an above-ground barrier. The rubble layer would slow drilling, rather than halt it, but can be expected to have excellent longevity. The tire layer can be expected to halt some drilling technologies and slow others; however, the longevity of such a layer is unknown. A barrier mound would have excellent longevity. As its effectiveness depends on persuading the driller to relocate, rather than preventing drilling, it is impossible to assess how effective this barrier would prove.

Finally, the assumption of no advances in drilling technology was made for the sake of keeping the issue traceable. It is possible that advances in drilling technology in the next century will render any engineered barriers ultimately ineffective, should the driller be sufficiently motivated to penetrate them. 


\section{References}

Adams, M. R., R. A. Carlson, and P. K. Brockman. 1981. Long-Term In Situ Disposal Engineering Study. Pacific Northwest Laboratories, Richland, WA. RHO-CD-1142.

Fayer, M. J., W. Conbere, P. R. Heller, and G. W. Gee. 1985. Model Assessment of Protective Barrier Designs. Pacific Northwest Laboratories, Richland, WA. PNL-5604.

Halsey, W. G., and R. D. McCright. 1987. Plan for Metal Barrier Selection and Testing for NNWSI. Lawrence Livermore National Laboratory, prepared for Nevada Nuclear Waste Storage Investigations Project, Las Vegas, NV. UCJD-2 1262.

Hora, S. C., D. von Winterfeldt, and K. M. Trauth. 1991. Expert Judgment on Inadvertent Human Intrusion into the Waste Isolation Pilot Plant. Sandia National Laboratories, Albuquerque, NM. SAND9O-3063.

McCright, R. D. 1995. Updated Candidate List for Engineered Barrier Materials. Lawrence Livermore National Laboratory, prepared for Yucca Mountain Site Characterization Project, Las Vegas, NV. UCRL-ID-1 19442.

Phillips, S. J. and J. N. Hartles. 1986. "Protective Barrier Systems for Final Disposal of Hanford Waste Sites, Waste Management” '86, Waste Isolation in the U. S., R. G. Post (ed.). University of Arizona, Tucson, AZ. Vol. 1, pp. 433-437.

Snyder, K. E., D. L. Gustafson, H. E. Huckings-Gang, J. J. Miller, and S. E. Rawlinson. 1995. Surficial Geology and Performance Assessment for a Radioactive Waste Management Facility at the Nevada Test Site. U.S. Department of Energy, Las Vegas, NV. DOE/NV/10833-25, UC721.

Tolan, T. L. 1993. The Use of Protective Barriers to Deter Inadvertent Human Intrusion Into a Mined Geologic Facility for the Disposal of Radioactive Waste: A Review of Previous Investigation and Potential Concepts. Sandia National Laboratories, Albuquerque, NM. SAND9 1-7097.

Trauth, K. M., S. C. Hora, and R. V. Guzowski. 1993. Expert Judgment on Markers to Deter Inadvertent Human Intrusion into the Waste Isolation Pilot Plant. Sandia National Laboratories, Albuquerque, NM. SAND92-1382.

U.S. Department of Energy. 1987. Disposal of Hanford Defense High-Level, Transuranic, and Tank Wastes, Final Environmental Impact Statement, Hanford Site. Richland, WA. DOEIEIS-01 13.

Walton, J. C., L. E. Plansky, and R. W. Smith. 1990. Models for Estimation of Service Life of Concrete Barriers in Low-Level Radioactive Waste Disposal. Idaho National Engineering Laboratory, Idaho Falls, ID. NUREG/CR-5542. 
Westerman, R. E. 1980. Investigation of Metallic, Ceramic, and Polymeric Materials for Engineered Barrier Applications in Nuclear-Waste Packages. Pacific Northwest Laboratory, Richland, WA. PNL-3484. 